\title{
SIZE EFFECT ON BEHAVIOR OF CRITICAL SHEAR CRACK IN REINFORCED CONCRETE BEAM USING DIGITAL IMAGE CORRELATION
}

\author{
A. BELBACHIR ${ }^{* \dagger}$, S.Y. ALAM ${ }^{\dagger}$, M. MATALLAH ${ }^{*}$, A. LOUKILI ${ }^{\dagger}$ \\ ${ }^{\dagger}$ University LUNAM Ecole Centrale de Nantes, Nantes, France \\ * University Abou Bakr Belkaid, Tlemcen, Algeria \\ E-mail : ahmed.belbachir@ec-nantes.fr
}

Key words: Size effect, Reinforced Concrete structures, Diagonal shear crack, Shear Strength.

\begin{abstract}
The shear strength of a reinforced concrete beam remains an issue of great interest in structural engineering. In addition, it is well known that the mechanical performance of real structure needs to take into account the phenomenon of "size effect". In this research, an experimental work was conducted to study the size effect and behavior of the critical shear crack in reinforced concrete beams without transverses reinforcement. In order to get these objectives, three points bending tests were performed on geometrically similar beams, with identical width of the cross section and varying effective height. The percentage of flexural reinforcement was set constant. DIC technique was used to monitor the crack width of diagonal shear crack, the crack profile and propagation during the failure process. By applying the DIC technique, a non-linear evolution of the crack width was observed for the three specimens.
\end{abstract}

\section{INTRODUCTION}

The behavior of the reinforced concrete beams under the shearing force is characterized by a sudden failure. Several tests were conducted to clarify and understand the principal mechanisms behind the shear failure $[1,2]$ and the transmission of the shear force to the supports. Researchers are based on the following mechanisms:

- Aggregate Interlock: this mechanism is based on the friction between the two lips of the cracks [3,4]. Where the capacity is influenced by the size and type (normal or lightweight) aggregates, surface roughness and shape and opening of the crack and the type of concrete (normal or high performance).

- Dowel Action: longitudinal flexural reinforcement plays a role in the transmission of the shear load [5] due to its shear rigidity. The latter is influenced by the diameter of the bar, and by the cover.

- Residual Tensile stresses: this mechanism is limited by the opening of the crack. When the opening of the crack does not exceed $0.1 \mathrm{~mm}$, tensile stresses can pass along the fissure [6].

- Un-cracked concrete zone (compression zone): it is characterized by the formation of the compression strut beyond the cracking zone to transmit the shear force at supports [7].

Several tests were conducted to understand parameters influencing the shear capacity of reinforced concrete structures [8-9]. For example, shear span to depth ratio where the change in this parameter leads to change in failure modes [8]; longitudinal reinforcement ratio and arrangement affect in the load level of failure in shear [8]. For a large value of the concrete compressive strength, shear capacity increases comparing with low 
values $[8,9]$. Studies were performed to identify the nonlinear dependence of the height at the nominal strength, where the shear strength of members without stirrups increases as the depth size decrease [11].

The objective of this paper is to identify and understand cracking in reinforced concrete members with same shear span to depth ratio a/d in different size of beams without transverse reinforcement. The DIC technique was used to extract the opening and evolution of the critical shear crack and it was found that this technique is able to describe the propagation of cracks. Finally, an analysis was performed of size effect in shear strength and compared with equation proposed with researchers [in reference 8], it has been noticed that the nominal shear strength, in peak load, decrease with increase in the effective height in the case of reinforced concrete beams without stirrups.

\section{EXPERIMENTAL WORK}

\subsection{Specimen geometry}

To investigate and study the behavior of crack in reinforced concrete beams without stirrups, an experimental work was carried out in GeM institute. The concrete beams in this study are geometrically similar, where all the beams have the same width $(b=200 \mathrm{~mm})$ and effective depth ranged from $200 \mathrm{~mm}$ to 600 $\mathrm{mm}$ as given in Table 1. As shown in Figure 1 the specimens have the same ratio between the shear span and the affective depth $(\mathrm{a} / \mathrm{d}=2.5)$.

Table 1: Test specimens design.

\begin{tabular}{ccccccc}
\hline Specimen & $\begin{array}{c}b \\
(\mathrm{~mm})\end{array}$ & $\begin{array}{c}h \\
(\mathrm{~mm})\end{array}$ & $d(\mathrm{~mm})$ & $\begin{array}{c}L \\
(\mathrm{~mm})\end{array}$ & $\begin{array}{c}\rho_{s} \\
(\%)\end{array}$ & $\begin{array}{c}\rho_{c} \\
(\%)\end{array}$ \\
\hline$D 1$ & 200 & 250 & 200 & 1000 & 1.5 & 0.5 \\
\hline$D 2$ & 200 & 450 & 400 & 2000 & 1.5 & 0.5 \\
\hline$D 3$ & 200 & 650 & 600 & 3000 & 1.5 & 0.5 \\
\hline
\end{tabular}

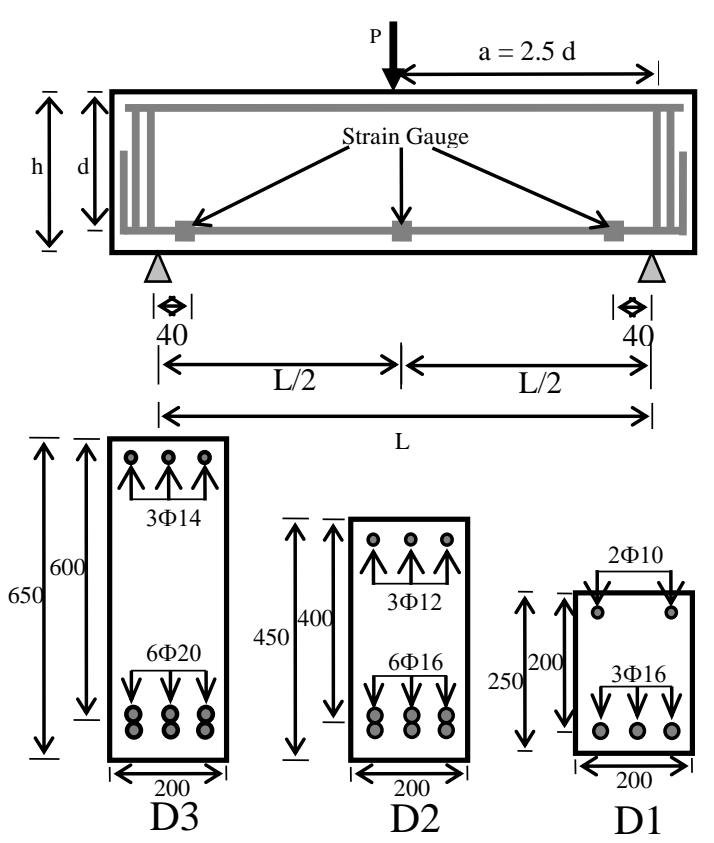

Figure 1: Test specimen details (dimensions in $\mathrm{mm}$ ).

The longitudinal reinforcement ratio was held constant $\left(\rho_{s}=1.5 \%\right)$ in the beams. In the extremities of the reinforcing bars, right angled hooks were provided. In addition, reinforcing bars were placed in the upper part of the beam with ratio of $\left(\rho_{c}=0.5 \%\right)$ to prevent the failure in compression. The detailing of the reinforcement configuration is shown in Figure 1 and Table 1.

\subsection{Material properties}

Specimens were cast by using a normal weight concrete that is made from the mix design illustrated in Table 2, where the maximum aggregate size is $d_{a}=16 \mathrm{~mm}$. In order to know the average of compressive and tensile strength, Compression and splitting tests have been made on cylindrical specimens $(110 \times 220 \mathrm{~mm})$ as summarized in Table 3 .

Table 2: Concrete mix design details

\begin{tabular}{ll}
\hline Cement (Portland 52.5$)$ & $347 \mathrm{Kg} / \mathrm{m}^{3}$ \\
\hline Sand & $790 \mathrm{Kg} / \mathrm{m}^{3}$ \\
\hline Coarse aggregate $(6-10 \mathrm{~mm})$ & $245 \mathrm{Kg} / \mathrm{m}^{3}$ \\
\hline Coarse aggregate $(10-16 \mathrm{~mm})$ & $815 \mathrm{Kg} / \mathrm{m}^{3}$ \\
\hline Water & $185 \mathrm{Kg} / \mathrm{m}^{3}$ \\
\hline
\end{tabular}


The reinforcing bars used in this test were deformed steel bars where the bar proprieties, yielding strength and elastic modulus, are listed in Table 3.

Table 3: Mechanical proprieties of concrete and reinforcement

\begin{tabular}{ll}
\hline \multicolumn{2}{c}{ Concrete proprieties } \\
\hline Compressive Strength, $f_{c}$ & $28.35 \mathrm{MPa}$ \\
\hline Tensile strength, $f_{t}$ & $3.31 \mathrm{MPa}$ \\
\hline Dynamic Modulus, $E_{c}$ & $30.0 \mathrm{GPa}$ \\
\hline \multicolumn{2}{c}{ Steel proprieties } \\
\hline Yielding Strength, $f_{y}$ & $500 \mathrm{MPa}$ \\
\hline Elastic Modulus, $E_{s}$ & $200 \mathrm{GPa}$ \\
\hline
\end{tabular}

\subsection{Test setup and instrumentations}

Three points bending tests (Figure 1) are carried out in order to get the global response of beams, where the beams D1 and D2 were loaded by using hydraulic testing machine MTS $500 \mathrm{kN}$. A system has been adapted to measure the displacement of each beam at mispan by using a laser sensor. At the longitudinal reinforcement, strain gauges were placed in different places (see Figure 1) for the acquisition of longitudinal strains during the test.

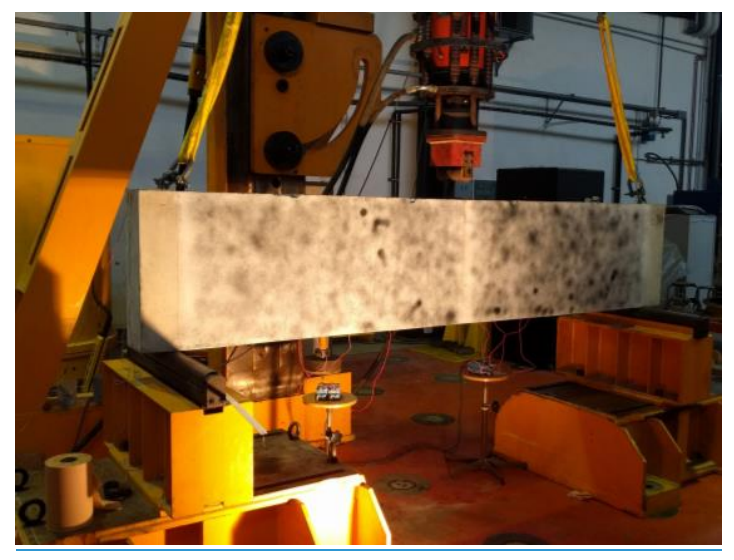

Figure 2: test configuration.

\subsection{Digital Images Correlation (DIC)}

To measure the displacement and to obtain the strains on surface, different techniques were developed such as strain gauges, LVTD and digital image correlation (DIC) and others. The DIC technique is an innovative non- contact way to facility the measuring. This technique was used on this experimental program in one side of the beam [12-13] by employing two cameras. The two cameras were placed away from the specimen surface and perpendicular to the center of the interested area, in order to record images every second. This method consists to measuring the displacement field on the surface between the reference image and a series of deformed images recorded during the experimental test.

\section{RESULTS AND DISCUSSION}

\subsection{General Behavior}

All beams were tested by using the same loading rate $(0.02 \mathrm{~mm} / \mathrm{s})$ in order to get the evolution of the applied force versus the displacement at mid-span of the beam (see Figure 3). As shown in Figure 3, the responses of the three beams show almost the same slope in zone A (Elastic behavior). The change in slope is due to the initiation of the bending crack in the middle of the beam a result of the presence of the bending moment. In the responses of the two beams D2 and D3 a single peak was observed. In the case of specimen D1, the response gives a second peak, this change is due to the growth of a second diagonal crack in the other side of the beam causing failure.

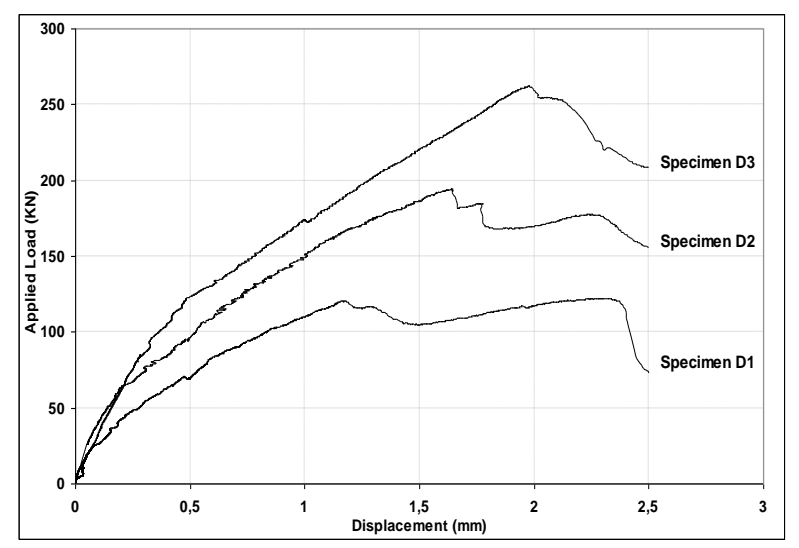

Figure 3: Load mid-span displacement curves.

During this work, only a failure mode was observed for the three specimens (See Figure 4). By analyzing the results of the DIC, it was observed that the diagonal crack is the 
continuity of the propagation of the bending crack. In the post-peak portion, it was noticed a third crack that propagates along the reinforcement caused by the delimitation between the steel and concrete (decrease in the bond strength).

Figure 5 shows the value of the strain of the flexural reinforcement under different loading rates; where for all the specimens, reinforcement yielding was not observed during the test. For the peak load, the three specimens did not present the same rate of strains. However, the smallest beam D1 gives a value superior than the value of the larger beam D3. this variation was caused by the presence of the effect of dowel action in D1 comparing with specimen D3 that shows a less capacity of dowel action in longitudinal reinforcement. As noticed in Figure 5, the strains in gauge 3 of D1 increase before reaching the maximum load leading to the presence of the first diagonal crack, where the gauge 1 start to rise after the peak load due to the formation of the second diagonal crack in the other side of the beam, and the same thing with the gauge 3 and gauge 1 in the specimen D3. While, in the medium beam D2 the change in the values of strains was observed only in one gauge (Gauge 1) after achieving the maximum load caused by the formation of the critical shear crack.

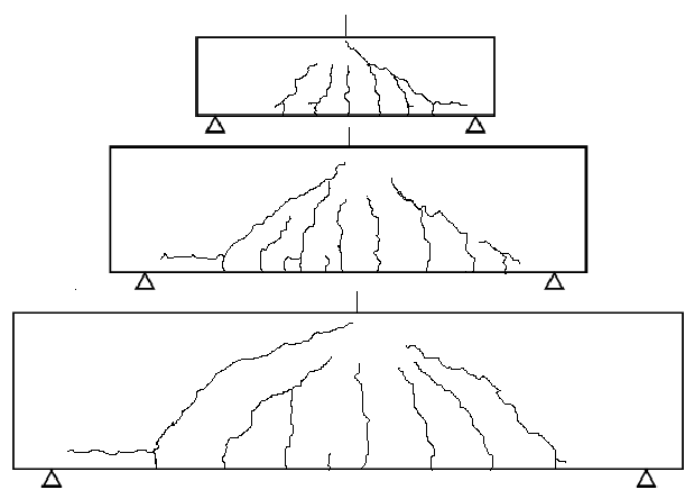

Figure 4: Crack patterns during the test.

\subsection{Crack opening}

Based on the processing of the results of DIC, the openings of the critical shear crack were extracted at the level of longitudinal reinforcement where it is observed the initiation of diagonal shear cracks. The curves Load - Opening $C_{w}$ were plotted in Figure 6, it is observed that the fracture critical crack
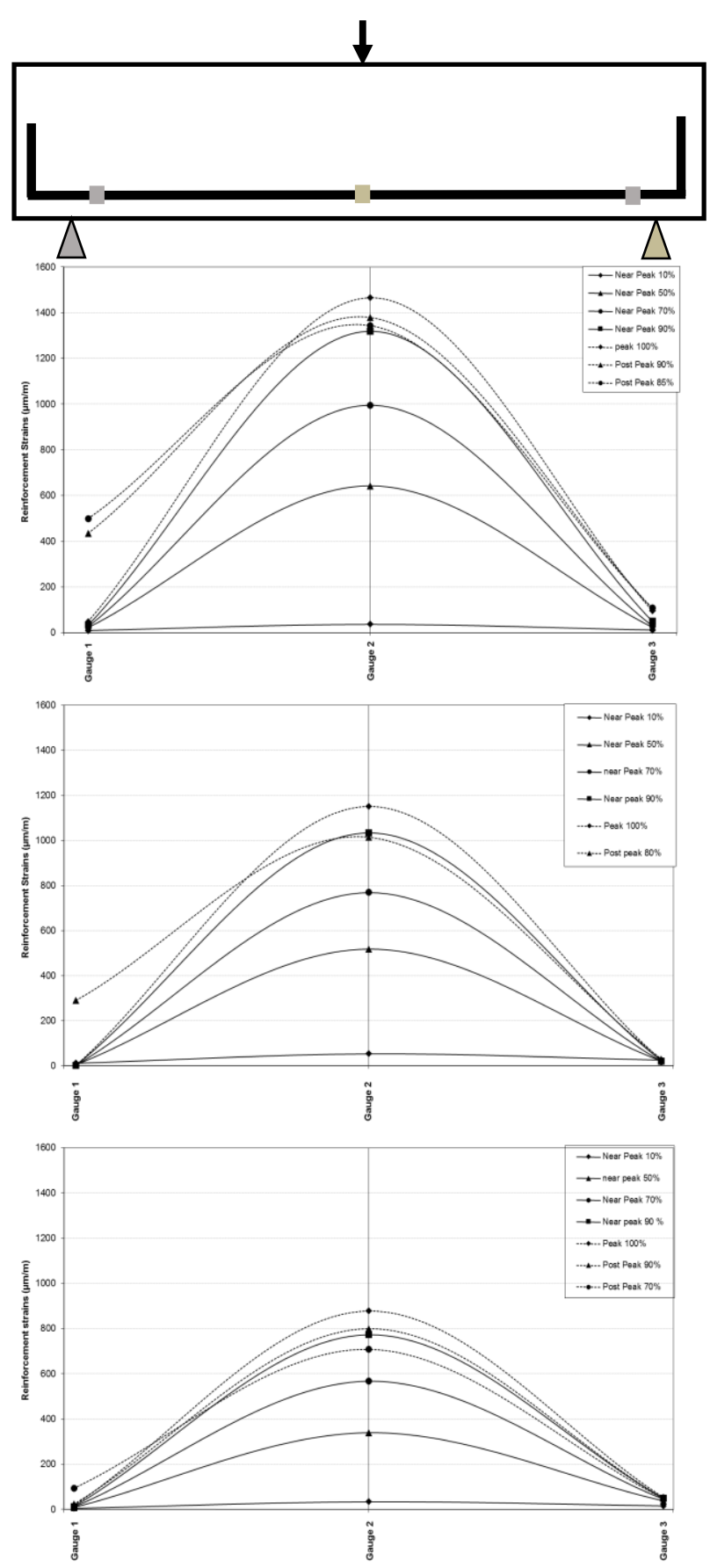

Figure 5: reinforcement strains relative to position and different loading state.

starts to open closer to the maximum load approximately between $0.9 P_{\max }$ and $P_{\max }$. The same behavior was observed for the three beams. By comparing the crack openings of the diagonal shear crack caused the failure, in peak load $P_{\max }$, a significant non-linear change 
was remarked between the three specimens. While, this non-linear shift was not only observed for maximum load but also in the post-peak part of all the beams. This nonlinear response is due to the effect that the beam with large size gives a large opening comparing with small size.

In this study, when the size increases an increase in the width of the critical shear diagonal crack were observed. Increasing the opening of the diagonal crack leads to reducing the effect of aggregate aggregates [4, 14].

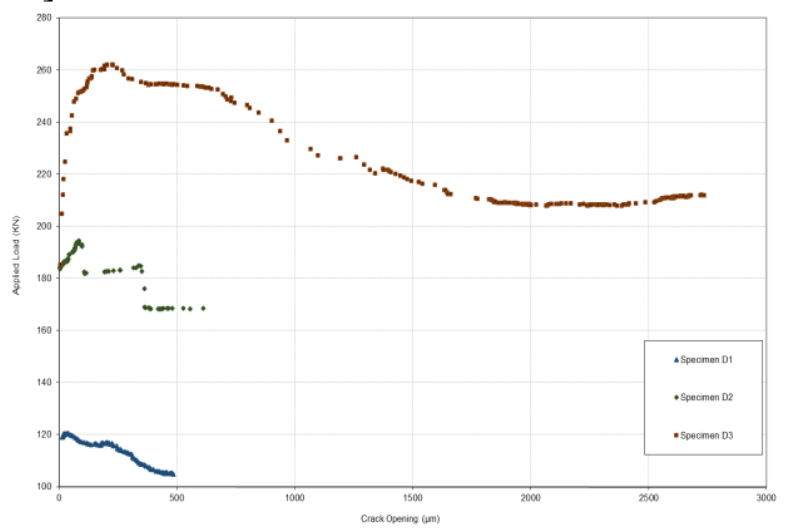

Figure 5: Applied Load - Crack opening curves.

\subsection{Crack opening and reinforcement strains:}

The openings of the critical shear crack diagonal and strains of reinforcements were plotted versus of the effective height of each beam in Figure 6 . Where the axis in the left represents the evolution of the crack opening of the three sizes in the peak load and $90 \%$ post-peak; while the COD in specimen D3 increases in a rapid manner compared to other specimens D1 and D2. The second axis shows the strains in gauge 1 where the growth of the critical shear crack, and the strains in the middle of the beam (Gauge 2). However, the response of the gauge 2 , in peak load, shows a nonlinear evolution comparing the values of the three members. Kept the ratio of reinforcement constant appears an increase in strains by decreasing the effective depth, and the same behavior was remarked for the gauge 2 after the formation of the diagonal crack. Considering the COD and strains of steel, it was observed that for large openings, low strains were recorded in the side of the critical crack (Gauge 1). This effect is due to the presence of a capacity of the mechanism of dowel action in the small beam D1 compared to the large beam D3 where the mechanism of aggregate interlock is significant.

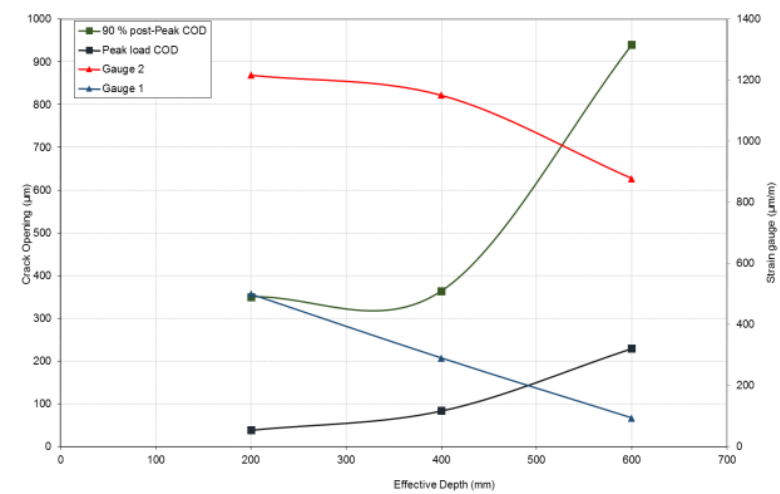

Figure 6: Crack opening and strains of reinforcement VS effective depth.

\section{SIZE EFFECT IN SHEAR STRENGTH}

Tests have been realized to study size effect in the reinforced concrete structures without transverse reinforcement $[8,9,11]$; they were concluded that the shear resistance decreases with increase in the size of specimen.

Bazant at al. [11] were proposed an equation to calculate the shear strength of reinforced concrete structures based on the fracture mechanics, as following:

$v_{u}=B f_{t}(1+\beta)^{-1 / 2}, \beta=d / d_{0}$

Where: $v_{u}$ the nominal shear strength, $d$ effective depth of the beam, $f_{t}$ tensile strength of concrete and $B, d_{0}$ constants.

The following table shows the maximum loads $P_{\max }$, shear forces $V_{\max }$, and nominal stresses $v_{n}\left(v_{n}=V_{\max } / b d\right)$ obtained from the tests of each beam and the values calculated with the equation of EC2 [15]. The following equation was applied to compare it with our results as shown in Figure 6.

The equation for calculating the shear force with EC2:

$v_{E C 2}=0.12 k\left(1000 \rho f_{c}\right)^{1 / 3}$

Where:

$k=1+(200 / d)^{1 / 2}(\mathrm{~mm})$ 
$\rho=0.0015$ ratio of longitudinal reinforcement. $f_{c}=28.35 \mathrm{MPa}:$ compressive strength on concrete.

Table 4: Test Results.

\begin{tabular}{ccccc}
\hline Specimen & $\begin{array}{c}P_{\max } \\
(\mathrm{kN})\end{array}$ & $\begin{array}{c}V_{\max } \\
(\mathrm{kN})\end{array}$ & $\begin{array}{c}v_{n} \\
(\mathrm{MPa})\end{array}$ & $\begin{array}{c}V_{E C 2} \\
(\mathrm{MPa})\end{array}$ \\
\hline \multirow{2}{*}{$D 1$} & 120.561 & 61.281 & 1.532 & \multirow{2}{*}{0.837} \\
& 110.234 & 55.117 & 1.378 & \\
\hline \multirow{2}{*}{$D 2$} & 194.571 & 97.285 & 1.216 & \multirow{2}{*}{0.715} \\
\hline \multirow{2}{*}{$D 3$} & 236.919 & 118.459 & 1.480 & \\
\hline & 262.024 & 131.012 & 1.091 & \multirow{2}{*}{0.660} \\
\hline
\end{tabular}

The results obtained were compared with the law of Bazant (equation (1)) and the equation of EC2 (equation (2)) in Figure 6, a good agreement was remarked between the law of Bazant and the results.

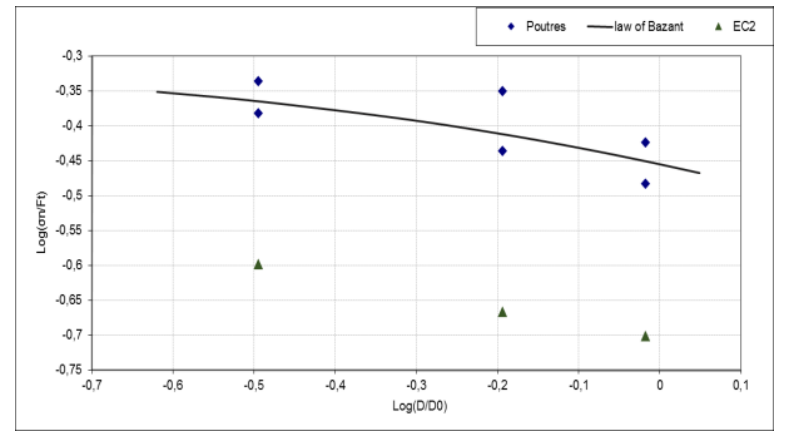

Figure 7: Size effect and Bazant law.

Where the comparison between the experimental results and the values obtained with the formula of EC2 shows a large difference due to the fact that the formula of EC2 underestimate the size effect in reinforced concrete beams without stirrups.

\section{CONCLUSIONS}

- The tests carried out were shown different behavior between the three specimens tested in terms of crack propagation, number of cracks and spacing between them, and the openings of the critical crack. This difference is due to the change of height and other parameters influencing modes and mechanisms of shear failure.

- The method DIC is found capable of giving propagation and profiles of various cracks (diagonal cracks) at different states of load. A non-linear evolution the diagonal crack.

- By combination of the results of DIC (COD) and strains gauges, it was observed that the capacity of the mechanism dowel action is low in large sizes compared with small sizes.

- Tests results show an increase of the shear stress with decreasing effective depth and give a good agreement with Bazant law, and a disagreement with the EC2 equation, caused by the caused by the underrating of the size effect in design of concrete structures.

\section{REFERENCES}

[1] Fernãndez Ruiz, M., Muttoni, A., Segaseta, J. 2015. Shear Strength of Concrete members without transverse reinforcement: A mechanical approach to consistently account for size and strain effects. Engineering Structures, 99: 360372.

[2] Campana, S., Fernãndez Ruiz, M., Anastasi, A., Muttoni, A. 2012. Analysis of shear transfer actions on one-way RC members based on measured cracking pattern and failure kinematics. Magazine Concrete Research. 56(6): 386:404.

[3] Walraven, J. 1980. Aggregate Interlock: a theoretical and experimental analysis. Ph.D. thesis, Delft university of technology, Delft, the Netherlands; 196.

[4] Walraven, J. C. 1981. Fundamental Analysis of Aggregate Interlock. ASCE J Struct. Div., 107(11): 2245-2270.

[5] Zararis, P.D. 1961. Shear strength and minimum shear reinforcement of reinforced concrete slender beams. Journal of the American Concrete Institute 2:203-214.

[6] Evans, R. H. \& M. S. Marathe. 1968. Micro cracking and stress-strain curves for concrete in tension. Matériaux et Constructions 1(1): 61-64.

[7] Sherwood, E. G., E. C. Bentz \& M. P. 
Collins. 2007. Effect of aggregate size on beam-shear strength of Thick slabs. Journal of the American Concrete Institute 104 (2): 180-190.

[8] Kani, G. N. J. 1966. Basics Facts concerning shear Failure. Journal of the American Concrete Institute, 63(6): 128147.

[9] Taylor, H. P. J. 1974. The fundamental behavior of reinforced concrete beams in bending and shear. American Concrete Institute Special Publication 42: 43-77.

[10] Kani, G. N. J. 1964. The Riddle of Shear Failure and Its Solution. Journal of the American Concrete Institute, 61(28): 441467.

[11] Bazant, Z. P., Kazemi, T. 1991. Size effect on diagonal shear failure of beams without stirrups. Journal of the American Concrete Institute 89(3): 268-276.

[12] Alam, S. Y., Loukili, A., Grondin, F., Rozière, E. 2015. Use of the digital image correlation and acoustic emission technique to study the effect of structural size on cracking of reinforced concrete. Engineering Fracture mechanics, 143: 1731.

[13] Alam, S. Y., Loukili, A. 2010. Application of digital image correlation to size effect tests of concrete. $7^{\text {th }}$ International Conference on fracture Mechanics of Concrete and Concrete Structures, pp: 191-197.

[14] Lantsoght, Eva O. L., Van der Veen, C., Walraven, J. C., and De Boer, A. 2016. Case study on Aggregate Interlock capacity for the shear Assessment of Cracked Reinforced-Concrete Bridge Cross Sections. Journal of Bridge Engineering, ASCE. 0401

[15] EC-2. Design of concrete structures part I: general rules and rules for buildings. Brussels: European Committee for Standardization. 2002. 